\title{
Real-time Tools in Classroom ${ }^{1}$
}

\author{
BAKONYI Viktória, ILLÉS Zoltán, Dr. ILLÉS Zoltán
}

\begin{abstract}
Today we are surrounded by IT devices and a lot of different applications from which more and more are usually work in real-time. These systems are mainly embedded systems but there are general operating systems which offers such possibilities too. Moreover, we can talk about real-time applications on the web as well. Therefore, it became very important for each informatician especially for future informatics teachers to know about the bases of this technology. Everybody knows the fact that each new technology appears sooner or later in education and finds its place in it. These new possibilities may give additional tools into teachers' hands. The question is whether they can live with the opportunity or not.
\end{abstract}

Keywords: real-time systems, teachers' training, classroom response systems

\section{Introduction}

Our public life is already supported by applications. We may follow the tracks of airplanes, trains, buses, use chatbots as customers, even we may meet with robot waiters (2018 https://bit.ly/2IhjUTw) or receptionists (2018 - https://bit.ly/2WawF70). For today autonomous cars became reality but real-time functionalities are built in normal cars too. There are more and more smart houses which are able to collect data about the environment or react to our requests in real-time. People are planning to build smart cities, which are able to handle common resources and meanwhile take care of the well-being of humans. It seems that we are living in the world of IoT (Internet of Things).

All of the previously mentioned possibilities describe computer-computer or human-computer interactions. Is there any newness in human-human interactions? Almost everybody has a smart phone with which people are able to speak with each other without any lagging. We use social networks to keep in contact or to get help in any problem we are facing to. What about education?

"Students inhabit a 21st-century world for 18 hours a day, and, all too often, educators put them in a 19th-century classroom for six hours of that day, and the students feel a tremendous disconnect. We bave a responsibility to teach them the skills to optimize these tools." (https://bit.ly/2FNB3m5)

Naturally, they must learn lifelong to keep on with their professions, but we have to offer a base on which they can build their future knowledge. Real-time world is around us, so we have to explain the ideas of real-time application features $[1,2,3]$. This technology appeared in the education as well therefore we can present RT educational tools and their usefulness. $[4,5,6,7]$

\section{Real-time systems}

\subsection{The Notion}

Before anything else we have to explain what, we mean under an RT system. Usually people think that a real-time system must be a very quick system, but it is a disillusion. The key is not the quickness of the operation but the existence of a deadline. It means that a system is real-time if the

\footnotetext{
${ }^{1}$ EFOP-3.6.3-VEKOP-16-2017-00001: Talent Management in Autonomous Vehicle Control Technologies - The Project is supported by the Hungarian Government and co-financed by the European Social Fund.
} 
response must finish within the given deadline. If no delay is acceptable then it is called a hardreal time system (a delay may cause a catastrophe) otherwise it is a soft real-time system. It is quite simple to understand and define it but how can we develop such systems? The solution is not easy at all!

\subsection{Architecture}

Frequently real-time systems are running on embedded systems which are created for a special goal. A typical RT system is a controlled system which collects data through its sensors and controls the environment with its actuators warranting the deadline of the response. (Figure 1.)

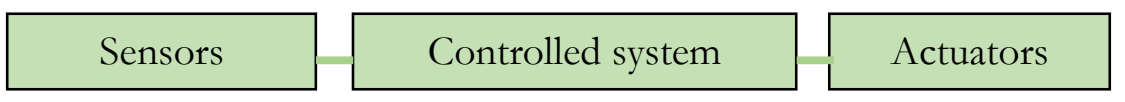

Figure 1. Model of a controlled system

Usually it executes only one process, which collects data and may give some kind of responses within a deadline, but nowadays general operating systems offer RT features too.

Classification of RT systems:

- Single task - running on a device without OS (Naturally the programmer has to know the detailed information about the execution time of a single instruction, the accuracy of the system clock, the IO operations and the timer.)

- Single task - running on a device with OS (not too difficult to calculate the execution time of a program, similar to the previous)

- Multitask - running on a device/computer with OS

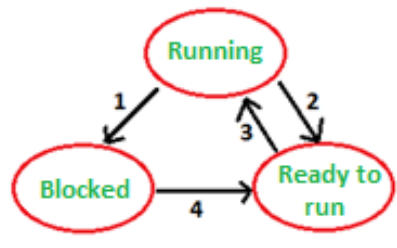

- The real interesting question in the case of a multiuser, multitask OS is: how can we ensure the deadline running together several different tasks, which are a possibly mixed set of normal and real-time processes. Which of the processes should run next? (Figure 2.)

- The work is done by the schedulers. The common idea is

Figure 2 Processes in different states

to give some extra priority level to the real-time processes and so they can get more resources to run. Let us see how interrupt \& priority handling may help.

- First the low priority interrupt arrives,

- Time for task switch - the interrupt handler has to be detected and loaded

- The lower priority handler just has started, but after a while a higher priority interrupt arrives with a close deadline. If the lower finishes the work, the deadline of the higher priority process is missed!

- Time for task switch - the higher interrupt handler has to be detected and loaded - the deadline is hold

- The lower priority handler may continue its work.

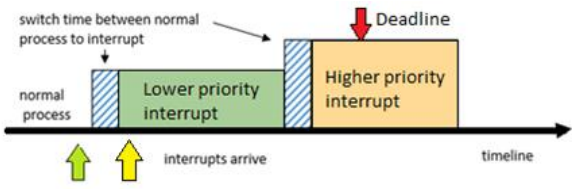

Figure 3. The deadline is missed Everything is fine! 


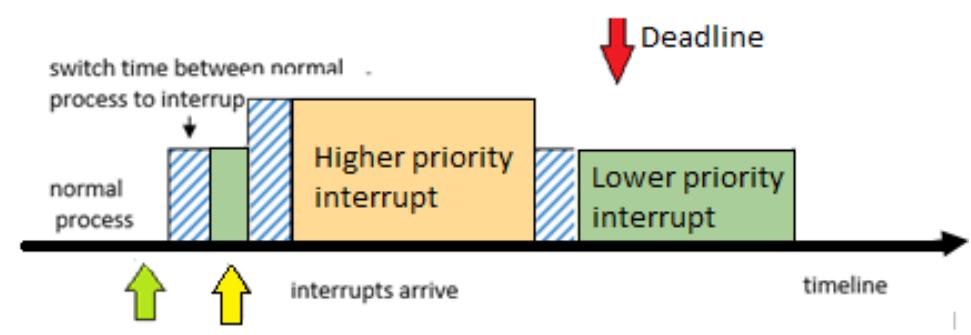

Figure 4. Nested (multilevel) interrupt handling

Naturally, the implementation is much more complicated, but the base idea(s) is shown in a subject named Operating Systems $\left(5^{\text {th }}\right.$ semester in programmers training, and a few semesters later in teachers' training). There are different ideas of schedulers and we have to calculate the speed of timers, interrupts, the latency etc. The scheduling is more difficult if we have several processors in the computer.

In the case of Suse Linux Enterprise RT we can define so called cpusets and dedicate tasks to a given cpuset - if the cpuset consists of only one CPU, then we are back at the case of a unique processor... In the system there is always a root cpuset which is dedicated for the OS. We may create shield cpuset which is not used by the OS it may be used only for special dedicated tasks at it is shown on Figure 5.

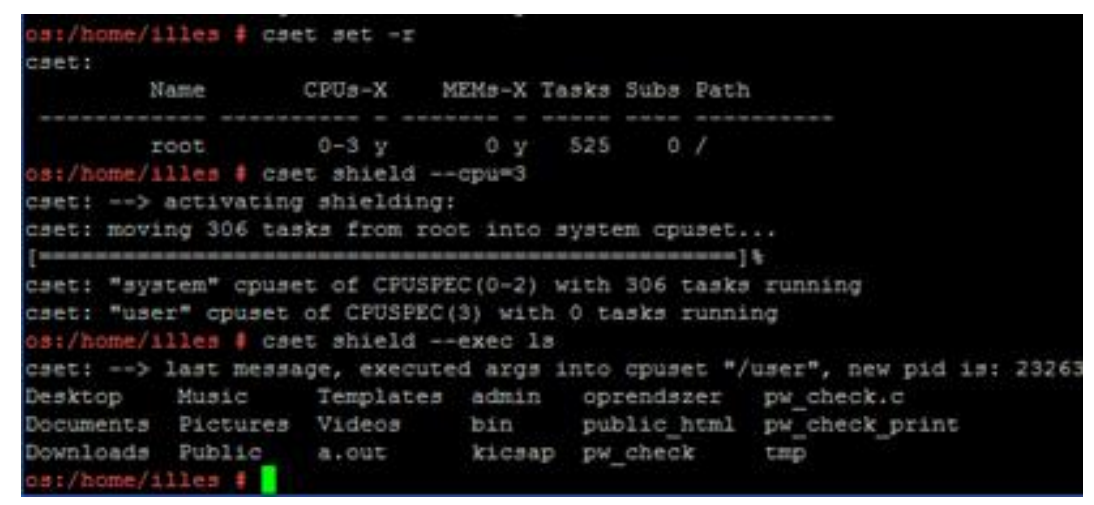

Figure 5. Usage of cset, shield in SuSe Linux

\subsection{Real-time Web - Notion}

If you understood the above described real-time notion you hardly believe that it may work in the case of web applications. You are right, but the real-time web has a different meaning! An RT web application does not need clients' requests to refresh the pages, while a classic web application does. Now there are several techniques the programmer may use to support RT web functionality like long polling, web sockets, etc. Using these technics, an RT web application can join to a service hub getting notifications from other participants without direct refreshing.

Such types of applications are used widely, e.g. the ARS (Audience Response System) is one of the most well-known. These types of systems are used to serve group meetings, virtual conference participations etc.

Sure, this type of applications can be used in education as well.

\subsection{Benefits of Using a Classroom Response System}

There are a lot of ready-made, platform independent, free of charge (mainly only part of it) CRS on the market. E.g. Kahoot (https://kahoot.com/ ),Socrative (https://www.socrative.com/), 
Spiral (https://spiral.ac/), VoxVote (http://www.voxvote.com/) and Sli.do (https://www.sli.do/ ) .

Our question should be why they are so popular in modern schools. The answer is quite complex as usual in real life. First today children are digital natives they like and always use their mobile devices as we emphasized previously. Remember the idea of Comenius learning should not be a task but a source for pleasure. We all know that doing something is much more effective than to read or listen to it - it was shown by E. Dale. Therefore, using a CRS in class each of the students is forced to deal with the topic. Practiced teachers know that nobody is able to pay attention too long, so some changings in activity may help to avoid mind wandering. Formative evaluations can be executed quickly, and we all know the benefits of them from the viewpoints of the teachers and the students as well. Meanwhile children may feel the personal attention of the teacher who may give immediate feedbacks to the results and it can mean a good motivation for them. Students, even shy ones are brave enough to involve them into the common work if the system gives anonymous possibilities. Furthermore, CRS helps in self-assessment as well - it makes possible to compare our own knowledge to the others'. With a modern CRS the teachers are able to collect data and make some data analyses later to enhance the effectivity of our teaching methods.

\subsection{E-Lection}

In our teaching practice we saw, the usage of such a CRS system is evident therefore we decided to integrate one of them to help students. As we started to use such a web-based RT Classroom Response System adding more interactivity to the lectures, we noticed a lot of problems.

Since we are not able to buy ready-made devices for each of the seats in the auditoriums, therefore we wanted to use the students' own devices. Moreover, we had a lot of preconditions (configurable authorization, post data analysing, etc) and they were missing from ready-made CRS system. So we had to implement an own CRS, called E-Lection which fits to our needs.

In the next some steps we describe our work.

1. Naturally, we had to make sure that the students have smart devices, that is why for preparation we made a survey in 2015/2016 academic year to explore the situation.

Survey about smart device usage

Circumstances: Google Form (to ensure the anonymity of students)

The survey available at http://bit.ly/1eGP5Hm (Hungarian)

Participants: 486 students from ELTE

Questions (interesting now): Do you have a mobile phone? Which type?

Table 1: Phone types - students' own

\begin{tabular}{|c|c|}
\hline Own phone types & ELTE students \\
\hline Smart phone & $92,4 \%$ \\
\hline Android & $68,4 \%$ \\
\hline Apple iPhone & $0,3 \%$ \\
\hline Windows Phone & $8,3 \%$ \\
\hline Other type & $15,3 \%$ \\
\hline Normal & $6,3 \%$ \\
\hline Nothing & $1,3 \%$ \\
\hline
\end{tabular}

Central-European Journal of New Technologies in Research, Education and Practice

Volume 1, Number 1, 2019. 
The results showed that we are ready to use a BYOD system (Bring Your Own Device) over 92 percentage.

2. In the $2017 / 2018$ academic year, in September we asked the students whether they think it is good to use a CRS system or not.

Survey about the idea of using a CRS

\subsection{Precondition: Previously they did not use any CRS systems in ELTE. To fill the survey} was not compulsory.

Circumstances: Google Form (to ensure the anonymity of students)

The survey available at https://bit.ly/2rcvR4P. (only in 0048ungarian)

Participants: 121 students who attended the 1 st semester and 76 students who attended the 5th semester.

Precondition: Previously they did not use any CRS systems in ELTE. To fill the survey was not compulsory.

Questions: (all together 13+1)

a) Would you consider it benefitting if you could use your own mobile device (phone, laptop, etc.) during lectures? (grade: $1-5$ )

b) Would you consider it useful if bilateral communication happened between the lecturer and students? (grade: $1-5$ )

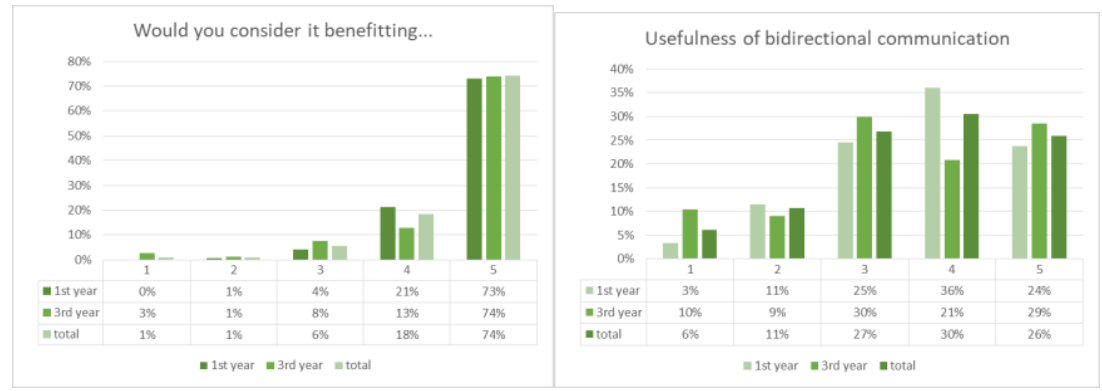

Figure 5. Results for question a and b.

The results showed that the students want to use their smart devices during lessons. More of them want to communicate and contact with teachers.

3. In $2017 / 2018$ academic year, we implemented and tested our system - at first time using it in Operating system subject. This subject is a compulsory subject of programming informatics at the 5th semester. We compared the students' results with and without using E-lection in this year. (In the time of writing this paper, we do not have final results from 2018/2019 academic year.) We compared the results of this semester and the results of the previous year (2016/2017 autumn semester). [5]

Circumstances: each year we had at about 200 students. 


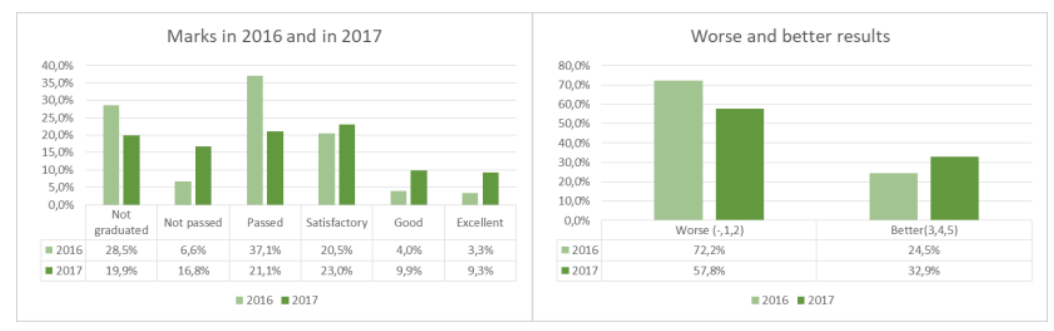

Figure 6. Compared results with and without E-Lection

As you can see on Figure 6, E-lection did not help too much for not graded or failed students, but the percentage of better results increased.

4. This academic year we retuned our system and tested again during Operating Systems subject. Usually the lectures started with one or two questions refreshing the basic ideas of the previous lesson and the students may answer them. In the middle of the semester we asked the students opinion about the usefulness of E-Lection.

Survey about the usefulness of E-Lection 2018/2019 academic year [7]

Circumstances: Google Form (to ensure the anonymity of students)

The survey available at bttps:/ / bit.ly/2CDsn10, bttps:/ / bit.ly/ 2JycD5o (English, Hungarian)

Participants: 84 students who filled the survey, Operating Systems (217 students all)

Questions: (There were more questions...)

a) In your opinion has E-Lection made classes more interesting? (grade: yes, no, sometimes)

\begin{tabular}{|l|l|l|}
\hline yes & No & sometimes \\
\hline $73,8 \%$ & $21,4 \%$ & $4,8 \%$ \\
\hline
\end{tabular}

The result shows on Figure 1., that they enjoy our E-Lection system.

b) How helpful are the teachers' questions and their discussions in understanding the most important concepts and principals?

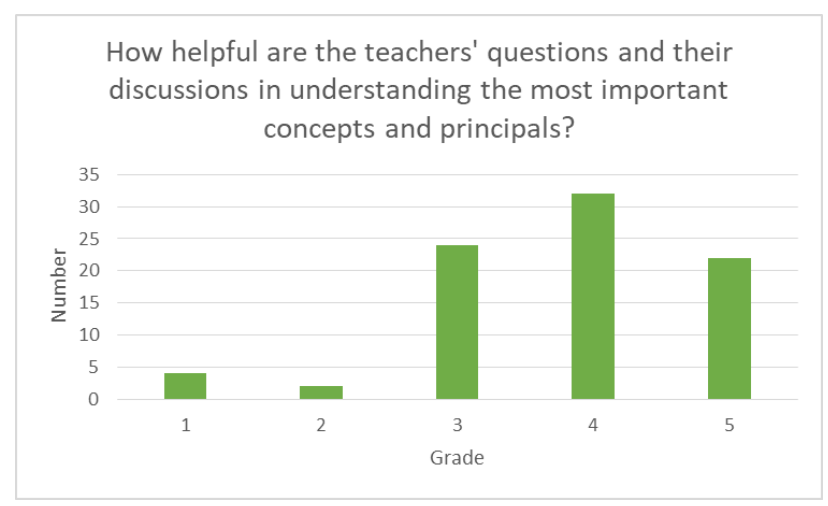

Figure 7. Usefulness of teachers' questions

5. To get a full panorama of CRS usage we decided to explore whether future teachers learn about CRS systems or not and what is the opinion of active teachers. We made a survey.

Survey about the usage of any kind of CRS, 2018/2019 academic year [4]

Circumstances: Google Form (to ensure the anonymity of students)

The survey is available at https://bit.ly/2KqLaBl (Hungarian)

Participants: 102 teachers/students who filled the survey,

Questions: (There were more questions...) 
a) The first thing we were interested in was that how many of them used CRS in school. The possible answers were never, rarely and often. (some of the persons skipped the question only 92 answers arrived.)

\begin{tabular}{|l|l|l|l|l|l|l|l|}
\hline Age & Numb & Never & $\%$ & Rarely & $\%$ & Often & $\%$ \\
\hline $20-35$ & 39 & 19 & 48,7 & 10 & 25,6 & 4 & 10,3 \\
\hline $36-50$ & 31 & 18 & 58,1 & 12 & 38,7 & 1 & 3,2 \\
\hline $50-$ & 32 & 20 & 62,5 & 6 & 18,8 & 4 & 12,5 \\
\hline Together & 92 & 57 & 61,3 & 28 & 30,1 & 9 & 9,7 \\
\hline
\end{tabular}

b) Do you think CRS is useful in school?

\begin{tabular}{|l|l|}
\hline Age & Usefulnes \\
\hline $20-35$ & $46,2 \%$ \\
\hline $36-50$ & $35,5 \%$ \\
\hline $50-$ & $40,6 \%$ \\
\hline Together & $41,2 \%$ \\
\hline
\end{tabular}

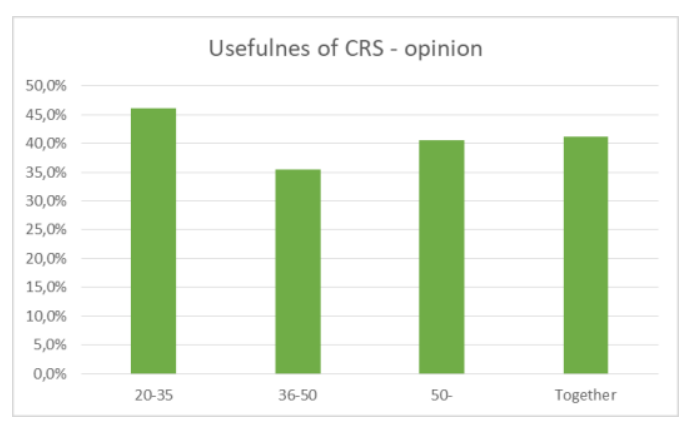

The result shows that teachers (over 35), who never learned about CRS in university are open to use new technologies and they keep on with IT technology! (It is true, that most of them were informatics teacher, therefore a general survey from human sciences may show another result.)

\section{Conclusion}

The spread of rich set real-time applications in daily life must change the focus points of education again. We must reorganize the content of subjects to present the newness of science and meanwhile we may use modern IT technology to make our teaching methods more inspiring. We implemented an own classroom system E-Lection and examined its reception and compared the achieved results. Our work is not finished yet, because we have to give new interesting features to the application according to the students' needs.

\section{References}

1 Illés, Z., Havancsák. K.: Real-Time Computer Measurement Control under Dos-Windows Operating System. In Annales Universitatis Scientiarum Budapestinensis de Rolando Eotvos Nominatae Sectio Computatorica XVII: pp. 193-199. (1998)

2 Tanembaum, A., Woodhull, A.: Modern Operating Systems, 2014. ISBN-13: 978-0133591620

3 Heizlerné Bakonyi, V, Illés, Z., Menyhárt, L. Viewpoints for the development of teaching contents in the field of informatics Acta Didactica Napocensia 6:(2) Paper 5. 10 p. (2013)

$4 \quad$ H. Bakonyi, V., Illés, Z.: Real time classroom systems in teachers training Lecture Notes in Computer Science 11169 : \& pp. 206-215. , 10 p. (2018)

DOI: $10.1007 / 978-3-030-02750-6 \quad 16$

5 Bakonyi, V., Illés,Z. : Experiences of Using Real-Time Classroom Response Systems In: František, Jakab (szerk.) 16th IEEE International Conference on Emerging eLearning Technologies 
and Applications : ICETA 2018, Košice, Szlovákia : Technical University of Kosice, (2016) pp. 51-56. , 6 p. DOI: 10.1109/ICETA.2018.8572042

$6 \quad$ H Bakonyi, V.; Illés, Z.: Real Time Systems In Embedded and Enterprise World (2018), DidMatTech Conference, 2018, Radom

7 H., Bakonyi, V.; Illés, Z.: Valós idejü oktatási rendszerek, In: Szlávi, Péter; Zsakó, László (szerk.) InfoDidact 2018, Budapest, Magyarország: Webdidaktika Alapítvány, (2019) pp. 51-58., 8 p.

\section{Authors}

\section{BAKONYI Viktória}

Eötvös Loránd University, Faculty of Informatics, Department of Media and Educational Informatics, Budapest, Hungary, e-mail: hbv@inf.elte.hu

\section{ILLÉS Zoltán, Ph.D.}

Eötvös Loránd University, Faculty of Informatics, Department of Media and Educational Informatics, Budapest, Hungary e-mail: zoltan.illes@elte.hu

\section{ILLÉS Zoltán}

Eötvös Loránd University, Faculty of Informatics, Department of Media and Educational Informatics, Budapest, Hungary e-mail: ilzo@inf.elte.hu

\section{About this document}

Published in:

CENTRAL-EUROPEAN JOURNAL OF NEW TECHNOLOGIES IN RESEARCH, EDUCATION AND PRACTICE

Volume 1, Number 1. 2019.

ISSN: 2676-9425 (online)

DOI:

10.36427/CEJNTREP.1.1.381

\section{License}

Copyright C BAKONYI Viktória, ILLÉS Zoltán Ph.D, ILLÉS Zoltán, 2019.

Licensee CENTRAL-EUROPEAN JOURNAL OF NEW TECHNOLOGIES IN RESEARCH, EDUCATION AND PRACTICE, Hungary. This article is an open access article distributed under the terms and conditions of the Creative Commons Attribution (CC-BY) license.

http://creativecommons.org/licenses/by/4.0/ 